\title{
openheart Sex differences in publication volume and quality in congenital heart disease: are women disadvantaged?
}

\author{
Sophie van Doren, ${ }^{1}$ Margarita Brida, ${ }^{2}$ Michael A Gatzoulis, ${ }^{3}$ Aleksander Kempny, ${ }^{4}$ \\ Sonya V Babu-Narayan, ${ }^{5}$ Ulrike M M Bauer, ${ }^{6}$ Helmut Baumgartner, ${ }^{7}$ \\ Gerhard Paul Diller
}

\begin{abstract}
- Additional material is published online only. To view please visit the journal online (http://dx.doi.org/10.1136/ openhrt-2018-000882).
\end{abstract}

To cite: van Doren S, Brida M, Gatzoulis MA, et al. Sex differences in publication volume and quality in congenital heart disease: are women disadvantaged?. Open Heart 2019;6:e000882. doi:10.1136/ openhrt-2018-000882

Received 10 July 2018 Revised 9 0ctober 2018 Accepted 10 November 2018

Check for updates

(C) Author(s) (or their employer(s)) 2019. Re-use permitted under CC BY-NC. No commercial re-use. See rights and permissions. Published by BMJ.

For numbered affiliations see end of article.

Correspondence to Professor Gerhard Paul Diller; Gerhard.Diller@ukmuenster.de

\section{ABSTRACT}

Background Women are underrepresented in leading medical positions and academia. The gender-gap in authorship of congenital heart disease (CHD) publications remains unknown. As determinants of gender equity in this field are poorly characterised, we aimed to quantify and characterise publications in CHD and to assess factors associated with female representation in research.

Methods and results We identified $35118 \mathrm{CHD}$ publications between 2006 and 2015 for which author gender could be ascertained. Overall, $25.0 \%$ of all authors were female. Women accounted for $30.2 \%$ and $20.8 \%$ of all first and senior authorship positions with great geographic heterogeneity. While globally female first and senior authorship increased by $0.8 \%$ and $0.6 \% / y e a r$, some geographic regions showed no improvement in gender representation. Significant predictors of female first authorship on logistic regression analysis were country gross domestic product, human development index, gender inequality index and a female senior author $(p<0.0001$ for all). Publications with a female lead author tended to be published in journals with a higher impact factor (IF) and to attract more citations compared with those with a male author. Mixed gender authorship was associated with higher IF and number of citations. Women were less disadvantaged when the analysis was confined to original research.

Conclusions While modest improvement in female authorship over time was noted, women remain underrepresented in contemporary academic CHD. Manuscripts with mixed gender authorship had higher IF and more citations. The main predictor of female first authorship was a female senior author. These data should inform policy recommendations regarding gender parity.

\section{INTRODUCTION}

A recognised imbalance exists in the participation of women in science and research globally. ${ }^{1}$ Women continue to be underrepresented in published research in various academic fields. Using academic productivity as a metric, gender-gaps in authorship have been reported across the spectrum of medical disciplines. ${ }^{2-8}$ Publishing in peer review journals continues to be an integral

\section{Key questions}

What is already known about this subject?

- Women continue to be underrepresented in leadingmedical positions and academia.

- Specific data on gender imbalance in congenitalheart disease is currently lacking.

What this study adds?

- Research in congenital heart disease remainsmale dominated.

- Manuscripts with a female first or senior authorand manuscripts with mixed gender authorship had higher impact factors and morecitations.

- Gender disparities are especially pronounced incertain geographic areas and this requires particular attention.

How might this impact on clinical practice?

- As it is unlikely that the problem will beself-rectifying, these data should inform policy recommendations to redressgender disparities.

part of the promotion system and is generally regarded to be essential for rising to the top tiers of academic medicine. ${ }^{4}$ A recent publication, for example, highlighted that women cardiologists were less likely than men to be full professors at US institutions even after accounting for factors associated with academic rank. ${ }^{9}$ Congenital heart disease (CHD) represents a relatively young field in cardiology and is an emerging area in cardiovascular science. Due to its dynamic nature and fast growth-with an estimated increase in the number of adults with CHD by $60 \%$ per decade ${ }^{10}$-it could be argued that this pioneering area is in constant need of gifted, enthusiastic colleagues and that entrenched barriers to academic career entry and progression for women would limit the pool of talent available and hence be undesirable. As specific data on gender imbalance in research performance in the field of CHD are currently lacking, the aims of our report 


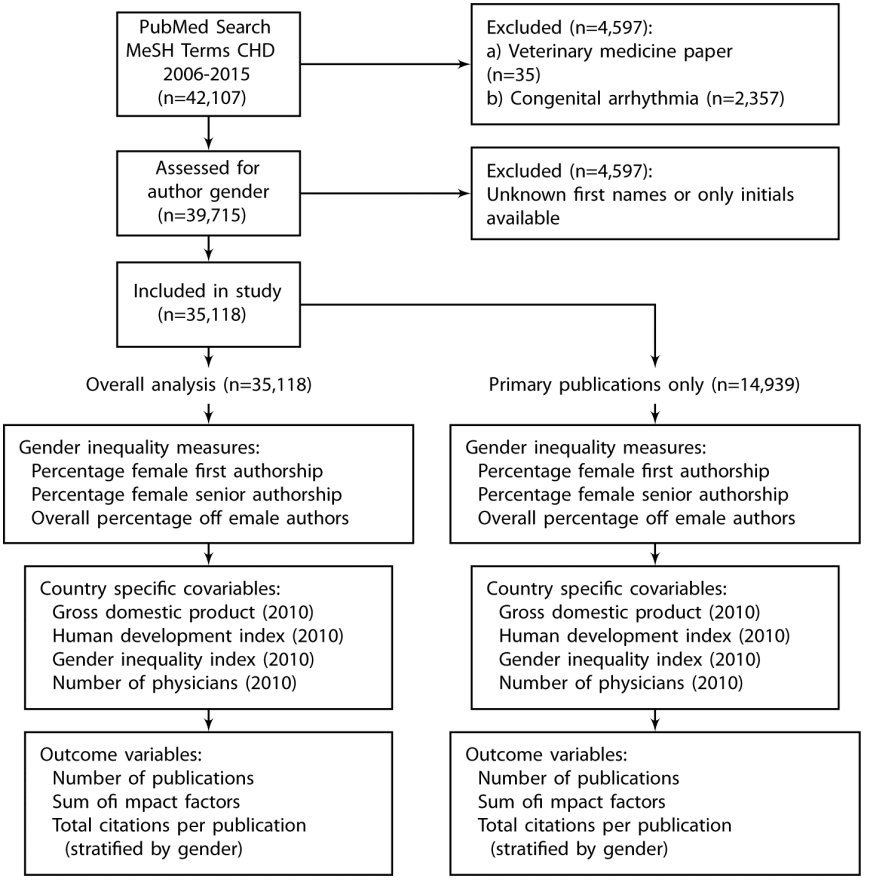

Figure 1 Flowchart of search strategy and included publications. CHD, congenital heart disease.

were: (1) to provide an overview over the magnitude of the 'gender gap' in CHD; (2) to assess temporal and geographical differences in female contribution to CHD research and (3) to provide insights into potential predictors of female authorship that in turn may inform future policy recommendations.

\section{METHODS}

The analysis included publications indexed in PubMed, focusing on CHD published over a 10-year period between 2006 and 2015. Publications of interest were initially electronically identified by using the major PubMed-MeSH term 'Heart Defects, Congenital'. Electronic queries were performed using R software (V.3.3.0, R Foundation for Statistical Computing) and the R-package RISmed. All retrieved articles underwent electronic filtering according to a prespecified protocol using both information available as part of the PubMed search and automatic text filtering of the manuscript title and abstract. Information on the search and categorisation strings used is presented in the online appendix of the manuscript. We excluded veterinary medicine publications and those focusing on electrical abnormalities of the heart in the absence of structural heart disease (eg, long-QT syndrome). The gender of the authors was analysed based on an established database linking authors' forenames to their respective gender, while accounting for country of origin (Gender API; gender-api.com). The database currently includes $>1.8$ million names from 178 countries. Articles with unavailable first names (eg, those providing only initials) and articles for which the first name could not be linked to author gender were excluded from the analysis. Publications were linked to the country of origin using the affiliation of the corresponding author or in case this was unavailable the affiliation of the first author.

To assess the relative quality of publications, impact factor (IF) data was retrieved for each paper based on the journal of origin and the year of publication. Journals without IFs for a given year were given an IF of zero but were counted as numbers of publications. To provide further information on the potential impact of individual publications, the number of citations a particular article attracted was also retrieved from the Thomson Reuters database and is provided. Data on the gross domestic product (GDP); the number of the practicing physicians and the national human development index (HDI) were obtained from the World Bank database (http://www. worldbank.org). In addition, information on the gender inequality index (GII) was retrieved from the United Nations Human Development Report. For all indices the 2010 data-representing the midpoint of our study period-was employed.

\section{Statistical analysis}

For statistical analyses R-package V.3.3.0 and MedCalc (V.17.2; MedCalc Software bvba, Belgium) were employed. Figures were produced using Tableau Desktop Software (V.10.1.3; Seattle, USA). Data were tested for normal distribution using the D'Agostino-Pearson test and visual inspection of Q-Q-plots. Comparison between groups for non-normally distributed data was performed by Mann-Whitney test and median and IQRs are provided. To assess predictors of female participation in research, logistic regression analysis was performed. To this end, female first authorship was used as a dependent variable. Independent variables were first tested on univariable analysis and significant parameters were subsequently included in a multivariable stepwise analysis. For continuous dependent variables, we employed non-parametric regression (providing Spearman's rank correlation coefficient) as well as univariable and multivariable leastsquares regression analysis after log-transformation to achieve normal distribution. To assess the adequateness of the automatic classification by area of research, 250 randomly selected publications were selected and these underwent manual classification. The agreement between the two methods was evaluated using an interrater agreement (Kappa) test and the K-value is reported. For all analyses, a two-sided $\mathrm{p}<0.05$ was considered significant.

\section{RESULTS}

The initial PubMed query identified 42107 publications related to $\mathrm{CHD}$ published over a 10 -year period between 2006 and 2015. After exclusion of papers focusing on veterinary medicine or congenital arrhythmia (without structural heart disease) as well as exclusion of publications for which author gender could not be ascertained, 35118 papers remained and were included in the analysis (figure 1). Table 1 provides an overview over journal and 
Table 1 Female contribution to overall, first and senior authorship during the study period stratified by overall publications and original research included

\begin{tabular}{lcc}
\hline & Overall & Original research \\
\hline $\begin{array}{l}\text { Number of publications } \\
\begin{array}{l}\text { Total citations (median } \\
\text { (IQR)) }\end{array}\end{array}$ & 35118 & 14939 \\
$\begin{array}{l}\text { Impact factor (median } \\
\text { (IQR)) }\end{array}$ & $2.23(1.20-3.63)$ & $6(2-15)$ \\
$\begin{array}{l}\text { Female authorship } \\
\text { overall (\%) }\end{array}$ & 25.0 & $2.55(1.35-3.85)$ \\
$\begin{array}{l}\text { Female first authorship } \\
(\%)\end{array}$ & 30.2 & 30.2 \\
\hline $\begin{array}{l}\text { Female senior } \\
\text { authorship (\%) }\end{array}$ & 20.8 & 36.6 \\
$\begin{array}{l}\text { Paper with mixed gender } \\
\text { authorship (\%) }\end{array}$ & 59.7 & 23.5 \\
\hline
\end{tabular}

Publication volume (top 10 countries)

\begin{tabular}{|lrr|}
\hline USA & 10965 & 5069 \\
\hline Japan & 2073 & 692 \\
\hline China & 2004 & 1096 \\
\hline UK & 1869 & 795 \\
\hline Italy & 1714 & 611 \\
\hline Germany & 1654 & 819 \\
\hline Turkey & 1621 & 483 \\
\hline Canada & 1349 & 690 \\
\hline India & 1113 & 273 \\
\hline France & 923 & 389 \\
\hline Publication quality (2impact factors) (top 10 countries) & \\
\hline USA & 36982.2 & 17372.6 \\
\hline UK & 6559.6 & 3071.8 \\
\hline Germany & 5285.8 & 2588.0 \\
\hline Canada & 4711.3 & 2681.8 \\
\hline Italy & 4433.8 & 1678.8 \\
\hline Japan & 3713.2 & 1712.1 \\
\hline China & 3201.4 & 2102.9 \\
\hline Netherlands & 3158.7 & 1761.9 \\
\hline France & 2865.1 & 1383.7 \\
\hline Switzerland & 1928.4 & 695.7 \\
\hline
\end{tabular}

In addition, cumulative publication numbers and impact factors of the top 10 countries contributing to research in the field of congenital heart disease are provided.

publication metrics as well as major countries contributing to published CHD research over the study period. In addition, it shows the percentage of female contributors in terms of overall, first and senior authorship. Women accounted for $25.0 \%$ of overall authorship positions, while contributing to $30.2 \%$ and $20.8 \%$ of all first and senior authorship positions, respectively (table 1). Stratifying publications irrespectively of gender by geographic region of origin revealed that the majority originated from North America (36.1\%), followed by Eastern Asia $(14.6 \%)$, Western Europe $(13.3 \%)$, Southern Europe
(8.7\%), Northern Europe $(8.1 \%)$ and Western Asia (2.5\%). In contrast, South America (2.3\%) and Africa $(0.6 \%)$ accounted only for a minority of publications.

\section{Relationship between gender and journal/publication metrics}

Overall, papers first authored by women contributed $30.5 \%$ of the overall cumulative IF, while those with a female senior author accounted for $21.0 \%$ of the sum of IFs. Assessing the association between female lead authorship and journal or publication metrics (IFs and citations) showed that papers with a female first author had a slightly higher median IF compared with those first authored by males (median [IQR]: 2.3260 [1.2330$3.8490]$ vs 2.2930 [1.1970-3.7300], $\mathrm{p}=0.008$; for female and male first authors, respectively; $+1.4 \%$ relative difference). No significant difference in IFs were found for female and male senior authors (median [IQR]: 2.2945 [1.1970-3.7080] vs 2.2304 [1.2020-3.7380], $\mathrm{p}=0.95)$. Publications with a mixed author panel (ie, both males and female authors) had a significantly higher median IF compared with purely male or female authored papers (median [IQR]: 2.3420 [1.2315-3.8270] vs 2.1810 [1.1550-3.6440], $\mathrm{p}<0.0001$; for mixed vs unisex authors, respectively; $+7.3 \%$ relative difference). Regarding number of citations, papers first or senior authored by women attracted significantly more citations compared with those with males in the respective authorship position (median [IQR]: 4 [1-11] vs 3 [1-8], $\mathrm{p}<0.0001$ [relative difference/paper+22.1\%] and 4 [1-10] vs 3 [1-9], $\mathrm{p}<0.0001$ [relative difference/paper+19.3\%]; for female vs male first and senior authorship, respectively). Also, papers with a mixed gender authorship composition had significantly more citations compared with papers with entirely male or female authors (median [IQR] 4 [1-12] vs $2[0-6], \mathrm{p}<0.0001$ [relative difference/paper+91.5\%]). On non-parametric regression analysis, the percentage of female authors correlated modestly with the publication IF $(\rho=0.043, p<0.0001)$ and the number of citations $(\rho=0.112, p<0.0001)$.

\section{Female contribution by geographic area}

The percentage of publications authored by women differed between geographic regions and countries. Table 2 and figures 2-4 provide a region-specific and country-specific overview over the situation. The data highlight, that on a global scale women authors tended to be underrepresented in Asia and some parts of Africa (although on the background of low overall publication volume). Visually assessing the figures suggests that especially Eastern and Northern European countries tend to have a larger percentage of female authors compared with other parts of the world.

\section{Temporal changes in female authorship contribution}

During the study period, the percentage of papers with a female first author increased from $27.2 \%$ in 2006 to $32.6 \%$ in 2015 (annual increase $0.8 \%$ /year, $\mathrm{p}<0.0001$ ), while an increase from $17.9 \%$ to $23.3 \%$ for female senior 


\begin{tabular}{lccccl}
\hline \multicolumn{7}{l}{ Table 2} & Female contribution to publications in congenital heart disease by geographic regions & \\
\hline Region & Total publications & $\begin{array}{l}\text { Overall female } \\
\text { authorship (\%) }\end{array}$ & $\begin{array}{l}\text { Female first } \\
\text { authorship (\%) }\end{array}$ & $\begin{array}{l}\text { Female senior } \\
\text { authorship (\%) }\end{array}$ & $\begin{array}{l}\text { Mixed gender } \\
\text { publication (\%) }\end{array}$ \\
\hline Northern America & 12314 & 31.5 & 32.0 & 22.2 & 59.1 \\
\hline Eastern Asia & 5001 & 21.4 & 20.7 & 12.2 & 56.2 \\
\hline Western Europe & 4530 & 28.5 & 33.2 & 18.3 & 67.2 \\
\hline Southern Europe & 2975 & 32.1 & 31.2 & 19.2 & 72.3 \\
\hline Northern Europe & 2756 & 30.2 & 37.3 & 22.1 & 59.6 \\
\hline Western Asia & 2111 & 21.8 & 21.3 & 15.7 & 52.3 \\
\hline Southern Asia & 1404 & 21.1 & 18.4 & 17.5 & 45.2 \\
\hline Eastern Europe & 919 & 38.5 & 39.6 & 27.5 & 67.9 \\
\hline South America & 773 & 39.5 & 38.6 & 27.0 & 69.0 \\
\hline Australia and New Zealand & 638 & 25.8 & 30.9 & 16.9 & 54.9 \\
\hline South-Eastern Asia & 246 & 33.5 & 35.2 & 23.2 & 61.8 \\
\hline Central America & 216 & 33.2 & 31.1 & 26.9 & 67.6 \\
\hline Northern Africa & 143 & 43.5 & 47.8 & 48.3 & 70.6 \\
\hline Western Africa & 35 & 6.1 & 9.1 & 5.7 & 22.9 \\
\hline Eastern Africa & 35 & 26.1 & 21.9 & 25.7 & 60.0 \\
\hline Caribbean & 29 & 31.4 & 35.7 & 31.0 & 48.3 \\
\hline Southern Africa & 27 & 27.3 & 20.0 & 14.8 & 25.9 \\
\hline Central Africa & 6 & 37.0 & 16.7 & 16.7 & 83.3 \\
\hline Overall & 35118 & 25.0 & 30.2 & 20.8 & 59.2 \\
\hline & & & & \\
\hline
\end{tabular}

authorship was found between 2006 and 2015 (annual increase $0.6 \% /$ year, $\mathrm{p}=0.0002$ ). The temporal changes, however, were found to differ between regions: while North America and some regions in Europe showed an increase in the percentage of female authorship, Eastern Europe and Western Asia had an actual decrease in female first authorship over the study period (figure 5). A similar picture emerged for overall female and senior

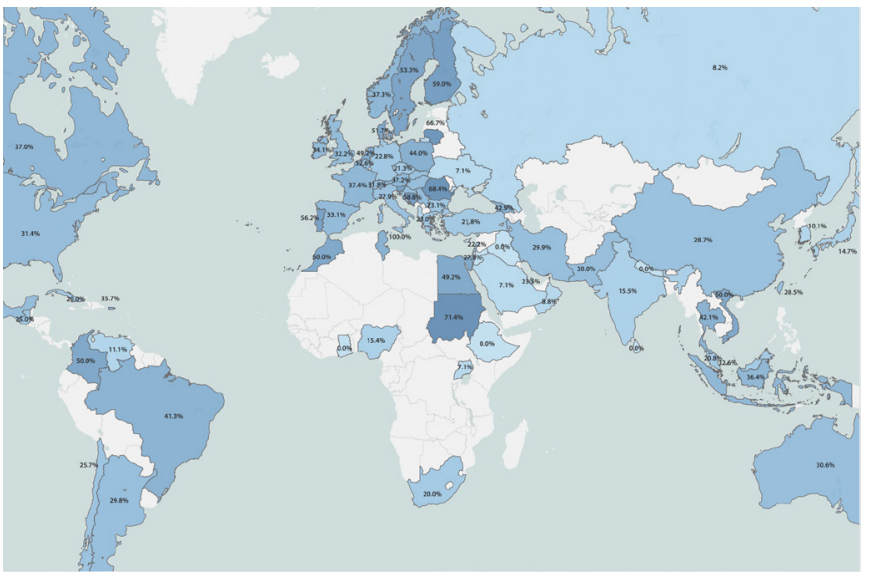

Figure 2 Geographic overview over the percentage of female first authors in congenital heart disease. Only countries with at least five publications during the study period were included. Darker colours indicate higher values. authorship as illustrated in online appendix figures A and $\mathrm{B}$.

\section{Predictors of female authorship}

On univariable logistic regression analysis, GDP, HDI, GII, number of physicians/capita and a female senior author of the publication correlated with the probability of the first author being female (table 3). As shown in

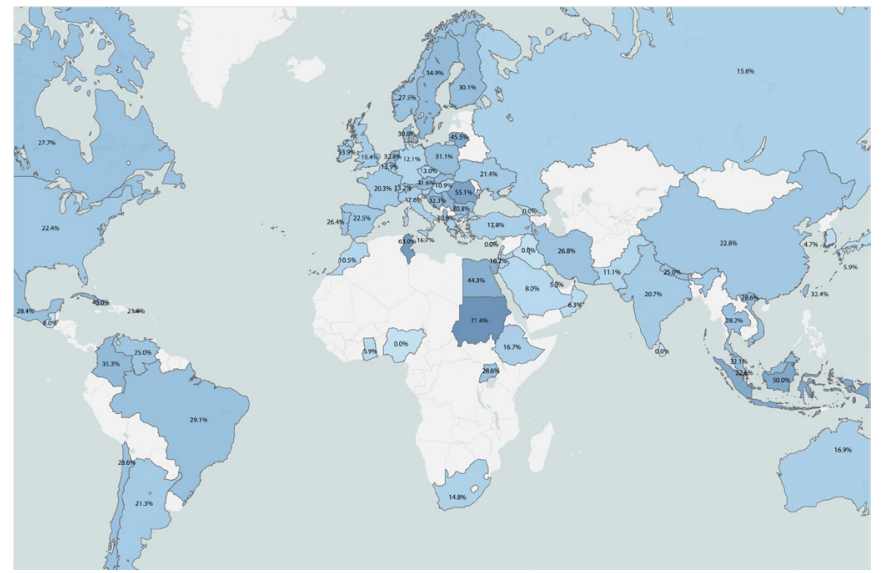

Figure 3 Geographic overview over the percentage of female senior authors in congenital heart disease. Only countries with at least five publications during the study period were included. Darker colours indicate higher values. 


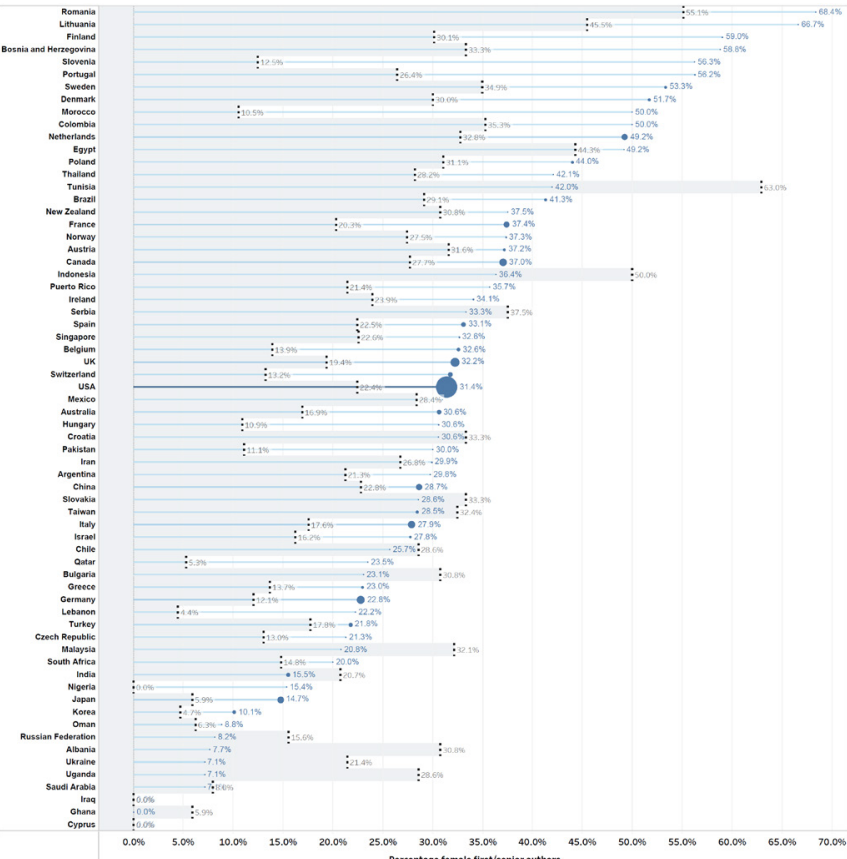

Figure 4 Female contribution by country. The grey bars represent senior authorship percentages, while the blue lines stand for first authorship. The area of the dot is proportional to the overall contribution of the respective country in terms of cumulative impact factors. Countries are sorted by percentages of female first authorship. Only countries with at least 10 publications during the study period are included.

table 4, on stepwise multivariable analysis GDP, GII and a female senior author remained significantly predictive of female first authorship. In fact, after accounting for GDP and GII, having a female as senior contributor was associated with an OR for female first authorship of $3: 1$. Assessing the percentage of female first authors by the gender of the last author confirmed this impression. Contributions with a male senior author had a female/ male ratio of first authors of $25.0 / 75.0 \%$, while for female senior authors this ratio was balanced at $50.5 / 49.5 \%$

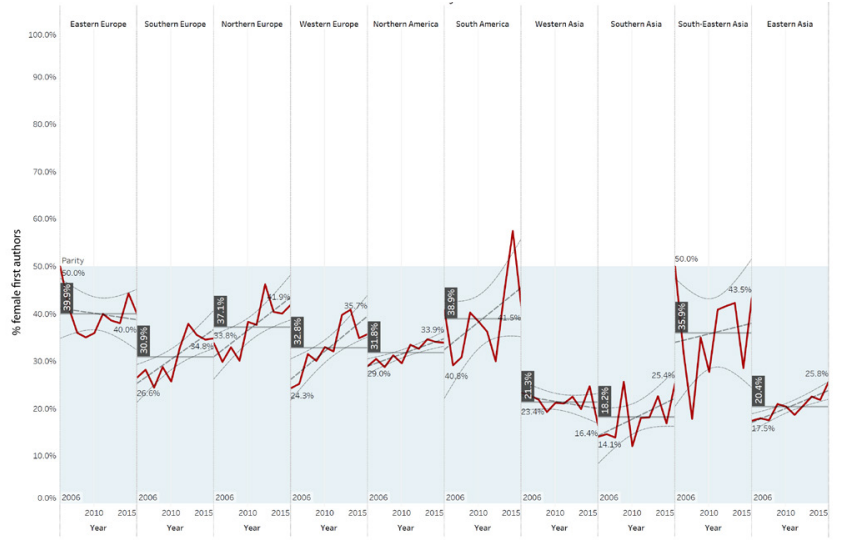

Figure 5 Temporal trends in female first authorship across various geographic regions. The vertical numbers indicate average percentage of female first authorship during the study period. The grey dotted lines indicate temporal trendlines with $95 \% \mathrm{Cl}$.
Female first authorship by type of publication and topic of research

Guidelines
Letter/Commentary
Case Report
Reviews/Editorials
Original research
Foetal
Paediatric without ACHD
Animal studies
In vitro
ACHD
Paediatric
Tetralogy of Fallot
Fontan
Systemic right ventricle
VSD
Ebstein anomality
Eisenmenger S.
ASD
Heart failure
Pulmonary hypertension
Endocarditis
Pregnancy in CHD
Pregnancy
Cardiac arrhythmias
Interventional studies
Echocardiography
Cardiac MRI

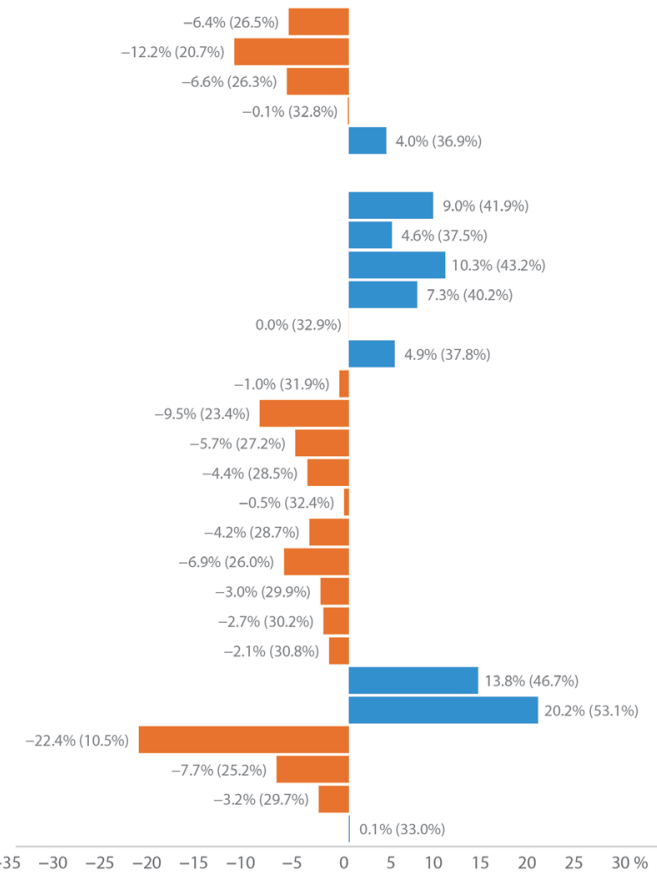

Figure 6 Female contribution by topics of research. The numbers in brackets represent the percentage of female first authors, while also relative differences to the average percentage of female first authors are shown.

$(\mathrm{p}<0.0001)$. On non-parametric regression analysis GDP per capita $(\rho=0.065, p<0.0001)$, HDI $(\rho=0.039$, $\mathrm{p}<0.0001)$, GII $(\rho=0.017, \mathrm{p}=0.006)$, number of physicians per capita $(\rho=0.06, p<0.0001)$ and a female senior author $(\rho=0.48, p<0.0001)$ were significantly associated with the percentage of female authors included in a publication. Table 5 shows the results of the univariable and multivariable parametric regression analysis after log-transformation of the number of female authors to account for non-normal distribution. The results illustrated in table 5 confirm the significant associations obtained from the non-parametric regression analysis while also providing multivariable adjustment.

Gender distribution by type of publication and focus of research and gender disparities in original research publications are described in detail in the online supplement of the manuscript.

\section{DISCUSSION}

The current study highlights the contemporary academic gender gap in the field of CHD. It illustrates that even in this relatively young and dynamic area of cardiology, women remain underrepresented compared with men in terms of publication output. Evidence that this is not a lack of ability is inherent in the trend for manuscripts with a female lead author to be published in journals with a higher IF and to attract more citations compared with those with a male lead author, that mixed gender authorship was associated with higher IF and number 


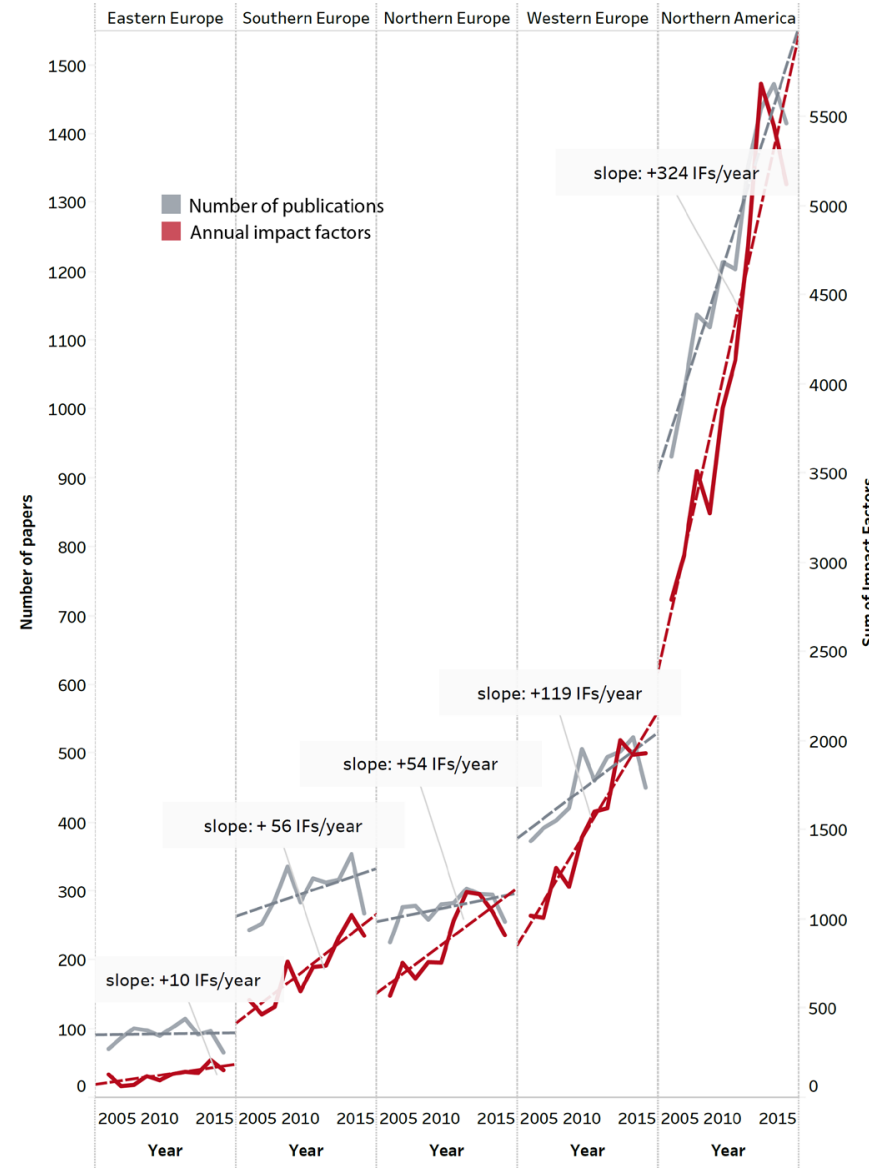

Figure 7 Temporal development of publication numbers and impact factors by geographic region. In addition to annual values, regression lines with slopes of change are provided for both measures.

of citations and that there is less disparity when analysis is confined to original research. Gender disparities are more pronounced in certain geographic areas and even within seemingly homogenous regions (such as Europe) large differences continue to persist. Interestingly, the strongest predictor of female first authorship was found to be a female academic in senior (last) authorship position. This finding may have policy implications, for example measures that enable establishment of a cadre of senior female leaders could result in female role models that subsequently act as catalysts for developing future junior female CHD researchers. While GDP-as a surrogate parameter for wealth and general level of economic development-was also positively correlated with equity in the field, it explains only a small fraction of the variability in the studied parameters of female involvement. In addition, some of the world's most wealthy countries, for example, Japan and Germany rank at the worst end of the spectrum in terms of female authorship participation. A notable exception are Eastern European countries exhibiting the highest proportion of female authors, approaching parity in terms of both first and senior authorship positions in some countries. However, Eastern Europe as a region is losing this relative advantage as we found a decrease in female academic output over the study period. This is in clear contrast to the general global trend of increased female contribution. Failing to foster available human capital and expertise in Europe and in many of its subregions could result in loss of competitiveness, for example, with respect to North America (see figure 5).

The reasons for the underrepresentation of women in academic medicine have been discussed in detail by various previous reports. Potential factors include cultural gender bias, traditional societal gender roles, harassment and sexism in the work environment, lack of adequate mentorship or inaccessible modes of mentorship/ networking, domestic responsibilities disproportionately affecting women and institutional settings unwelcoming to part time or flexible working professionals. ${ }^{112}$ Women may be subject to constrained rather than free choices as a result of these potential factors, which means they do not favour academic CHD. Subjecting women to gender microaggression may negatively affect their performance and reduce motivation. ${ }^{13} 14$ Furthermore, women physicians have been found to be disadvantaged in terms of grant funding available. Previous US data suggest that female applicants receive smaller grants compared with male applicants ${ }^{15}$ and this may negatively affect future professional opportunities for women in academic medicine. These factors, in combination, result in barriers even in geographic settings with a high proportion of female physicians and low overall gender inequality. Scandinavian studies suggest that despite favourable general cultural norms and equal opportunities laws, women are much less likely to achieve medical leadership positions or participate in decision making regarding academic research. ${ }^{16}$ Beyond these general challenges, women in specific geographic settings are subject to worse discrimination due to outdated cultural norms or expectations and disproportionate burden of motherhood. ${ }^{12}$ These factors have been cited to explain why women tend to be less likely to choose procedure-orientated medical subspecialties compared with their male peers. ${ }^{17}$ Within Europe, Eastern Europe emerged as a relatively equitable subregion in the current study. This is probably due to historic reasons, including the feminisation of medicine in the former Soviet Union and countries within its sphere of influence. ${ }^{12} 18$ It has been reported that women comprised approximately $70 \%$ of the physician workforce in the Soviet Union during the communist era. ${ }^{18}$ However - as a caveat-some have also highlighted the relatively low social status of the medical profession as a whole and the fact that most women occupied rank-andfile positions, with the dominant figures continuing to be male in this pre-reform era. ${ }^{12}{ }^{18}$ Nonetheless, the current study highlights that academic CHD medicine continues to be more equitable in the East European regions, suggesting that women are not necessarily marginalised into providing routine clinical care but rather contribute significantly to academic research and knowledge gain in the field. Perhaps disturbingly, the relative contribution 
Table 3 Univariable predictors of female first authorship on stepwise logistic regression analysis

\begin{tabular}{|c|c|c|c|}
\hline Parameter & OR & $95 \% \mathrm{Cl}$ & $P$ value \\
\hline GDP in 10000 US\$/capita (2010) & 1.0638 & 1.0491 to 1.0787 & $<0.0001$ \\
\hline Number of physicians per 1000 inhabitants (2010) & 1.0973 & 1.0702 to 1.1252 & $<0.0001$ \\
\hline Human development index (2010) & 3.4497 & 2.5881 to 4.5981 & $<0.0001$ \\
\hline Gender inequality index (2010) & 0.4555 & 0.3784 to 0.5484 & $<0.0001$ \\
\hline Senior author female & 3.0659 & 2.8990 to 3.2425 & $<0.0001$ \\
\hline \multicolumn{4}{|l|}{ By Subregion } \\
\hline Australia and New Zealand & 0.9484 & 0.7959 to 1.1302 & ns \\
\hline Caribbean & 1.1786 & 0.5435 to 2.5557 & ns \\
\hline Central America & 0.9562 & 0.7101 to 1.2876 & ns \\
\hline Eastern Africa & 0.594 & 0.2567 to 1.3746 & ns \\
\hline Eastern Asia & 0.555 & 0.5113 to 0.6024 & $<0.0001$ \\
\hline Eastern Europe & 1.3911 & 1.2113 to 1.5976 & $<0.0001$ \\
\hline Middle Africa & 0.4243 & 0.0496 to 3.6331 & ns \\
\hline Northern Africa & 1.9447 & 1.3894 to 2.7219 & 0.0001 \\
\hline Northern Europe & 1.2648 & 1.1589 to 1.3803 & $<0.0001$ \\
\hline South America & 1.3356 & 1.1485 to 1.5532 & 0.0002 \\
\hline South-Eastern Asia & 1.1517 & 0.8688 to 1.5267 & ns \\
\hline Southern Africa & 0.5304 & 0.1989 to 1.4142 & ns \\
\hline Southern Asia & 0.4798 & 0.4145 to 0.5553 & $<0.0001$ \\
\hline Southern Europe & 0.9622 & 0.8819 to 1.0498 & ns \\
\hline Western Africa & 0.2121 & 0.0647 to 0.6956 & 0.0105 \\
\hline Western Asia & 0.5737 & 0.5127 to 0.6420 & $<0.0001$ \\
\hline Western Europe & 1.0564 & 0.9817 to 1.1369 & ns \\
\hline (Reference category North America) & & & \\
\hline
\end{tabular}

Significant $p$ values are in bold.

GDP, gross domestic product; ns, not significant.

of women to academic CHD medicine in these regions is, however, now on the decline. We can only speculate about the reasons for this finding. Potential explanations include a 'brain drain' through an exodus of physicians to countries with better working conditions and more

Table 4 Multivariable predictors of female first authorship on stepwise logistic regression analysis

\begin{tabular}{llll}
\hline Parameter value & OR & $\mathbf{9 5 \%}$ Cl & P value \\
\hline $\begin{array}{l}\text { GDP in } 10000 \text { US\$/ } \\
\text { capita (2010) }\end{array}$ & 1.0451 & 1.0278 to 1.0626 & $<0.0001$ \\
$\begin{array}{l}\text { Number of physicians } \\
\text { per } 1000 \text { inhabitants } \\
\text { (2010) }\end{array}$ & - & - & ns \\
$\begin{array}{l}\text { Human development } \\
\text { index (2010) }\end{array}$ & - & - & $n$ \\
$\begin{array}{l}\text { Gender inequality index } \\
\text { (2010) }\end{array}$ & 0.5129 & 0.4115 to 0.6393 & $<0.0001$ \\
\hline $\begin{array}{l}\text { Senior author female } \\
\text { (2.0341 }\end{array}$ & 2.8640 to 3.2144 & $<0.0001$ \\
\hline
\end{tabular}

Significant $p$ values are in bold.

GDP, gross domestic product; ns, not significant. favourable remuneration structures, insufficient funds available for research or inadequate support for the field by leaders in cardiovascular medicine affecting the female workforce more than the male.

Improving career trajectories of female and male colleagues may require a combination of several approaches including provision of adequate support, fair remuneration structures, removal of structural and cultural barriers that prevent entry or turn women away from academic $\mathrm{CHD}$, and redressing hierarchical structures whereby all the top tier positions are occupied by men. ${ }^{18}$ Appropriate positive measures may include mentorship/sponsorship programmes and adequately funded local professional development programmes to support women who do choose academic CHD. This may also be required to address underrepresentation of women in surgical and interventional cardiology (transcatheter or electrophysiological) which have growing importance for long-term CHD clinical care. Lower participation of women in these CHD invasive subspecialties may in turn result in reduced participation in related clinical research. Consistent with this is our 
Table 5 Association between country characteristics as well as female senior authorship and percentage of female authors as a dependant variable on parametric regression analysis

\begin{tabular}{lcc}
\hline Parameter & $\begin{array}{l}\text { Correlation } \\
\text { coefficient }\end{array}$ & P value \\
\hline Univariable analysis & 0.0336 & $<0.0001$ \\
$\begin{array}{l}\text { Number of physicians per 1000 } \\
\text { inhabitants (2010) }\end{array}$ & 0.0477 & $<0.0001$ \\
$\begin{array}{l}\text { Human development index (2010) } \\
\text { Gender inequality index (2010) }\end{array}$ & 0.0353 & $<0.0001$ \\
$\begin{array}{l}\text { Senior author female } \\
\text { Multivariable analysis }\end{array}$ & Coefficient & P value \\
\hline GDP in 10000 US\$/capita (2010) & -0.0803 & 0.32 \\
\hline $\begin{array}{l}\text { Number of physicians per 1000 } \\
\text { inhabitants (2010) }\end{array}$ & 0.4108 & $<0.0001$ \\
\hline Human development index (2010) & 0.6736 & 0.33 \\
\hline Gender inequality index (2010) & 0.027 & 0.25 \\
\hline Senior author female & 0.3412 & $<0.0001$ \\
\hline
\end{tabular}

Significant $p$ values are in bold.

GDP, gross domestic product.

finding that women are disproportionately more likely to publish research related to fetal medicine or pregnancy outcomes, rather than, for example, electrophysiology or interventional cardiology (figures 6 and 7). To avoid a 'glass ceiling' effect mediated by peer regulation, female role-models/sponsors are urgently required to support younger female colleagues and to provide them with the informal socialisation and support generally available to men. ${ }^{18}$ In fact, this notion is supported by the current data, as we found that $50 \%$ of the first authors on papers senior authored by a female colleague were women. This is in contrast with the ratio of approx. $1 / 4$ for male senior authors.

In addition, department chairs should ensure that able juniors achieve milestones required for promotion and ultimately tenure positions regardless of whether they are female or male and must take care to avoid unconscious bias. Furthermore, a culture shift towards enabling balance of clinical and scientific responsibilities as well as family-friendly initiatives to enhance career for male or female parents should be advocated. ${ }^{11}$ To this end, strategic planning and increased transparency within organisations appear beneficial and need to be addressed at system level. As highlighted by Gottlieb, the possibility of formal sponsorship arrangements rather than mere mentorship should also be explored. Sponsorship has been defined essentially as a mentor with 'significant organisational influence ... willingness to advocate for protégées ... competitive assignments (and) leadership opportunities'. ${ }^{19}$ Overall, we contend that the results of the current study concur with previous findings supporting strategic investment in career development programme for women in the field of CHD. ${ }^{20} 21$

Our results highlight the importance of diversity in research. Publications with a mixed gender authorship panel were published in journals with a significantly higher IF and attracted significantly more citation compared with those from a single sex authorship panel. This finding is consistent with previous data ${ }^{19}$ and underlines the business case for promoting gender diversity and equity beyond mere fairness reasons. We also found no evidence of lower quality of research published by women (both in terms of the journal's IF and the number of citations). This is consistent with previous reports correlating clinical outcomes with physicians' gender. ${ }^{22}$

\section{Limitations}

The gender of the authors was determined by automatic recognition and cross-checked with a large database of first names accounting for the country of origin of the author. While some names could not be linked to author gender, all major geographic regions relevant to the current study are well represented in the underlying database and it appears unlikely that systematic bias was introduced by the process. We cannot exclude the possibility that the higher average IFs achieved by females are-at least in part-due to a country effect, that is, more women authors are located in countries with generally higher IF counts. However, sensitivity analyses including only North America, Western and Northern Europe confirmed a slightly higher median IF for women first and last authors (2.618 vs $2.614 ; \mathrm{p}=0.34$ and 2.619 vs $2.606 ; \mathrm{p}=0.19$ for female first and senior authors, respectively). Despite being a recognised individual evaluation criterion in research, we did not include data on the H-Index in the current analysis. This is due the fact that this information was not available to us and because H-Index is a cumulative measure, whereas we were interested in temporal trends. Further studies are required to address this issue.

\section{CONCLUSION}

Research in CHD remains male dominated, yet manuscripts with mixed gender authorship had higher IF and more citations. Gender disparities are especially pronounced in certain geographic areas and this requires particular attention. North and East European countries were found to be less inequitable than most other geographic settings though Eastern Europe is regressing on gender equity and thus in the process of losing its comparative advantage. The main drivers of gender equality were a senior female author and cultural factors. As it is unlikely that the problem will be self-rectifying, these data should inform policy recommendations to redress gender disparities.

\section{Author affiliations}

${ }^{1}$ Department of Cardiology III - Adult Congenital and Valvular Heart Disease, University Hospital Muenster, Muenster, Germany

${ }^{2}$ Cardiology, School of Medicine, University of Zagreb, Zagreb, Croatia ${ }^{3}$ Heart Centre and Centre for Pulmonary Hypertension, Royal Brompton Hospital, London, UK 
${ }^{4}$ Adult Congenital Heart Disease, Royal Brompton Hospital, London, UK ${ }^{5} \mathrm{NIHR}$ Cardiovascular Biomedical Research Unit, Royal Brompton and Harefield NHS Foundation Trust, National Heart and Lung Institute, Imperial College, London, UK ${ }^{6}$ Competence Network for Congenital Heart Defects, DZHK (German Center for Cardiovascular Research), Berlin, Germany

${ }^{7}$ Cardiology and Angiology, University Hospital Muenster, Muenster, Germany

Acknowledgements We acknowledge support by Open Access Publication Fund of University of Muenster.

Contributors All authors have contributed to the design and critical revision of the manuscript. SvD and GPD analysed the data and wrote the manuscript.

Funding This project has been kindly supported by the Karla Völlm charitable foundation (EMAH Stiftung Karla Völlm), Krefeld, Germany. SVB-N is supported by the British Heart Foundation (FS/11/38/28864).

Competing interests None declared.

Patient consent for publication Not required.

Provenance and peer review Not commissioned; externally peer reviewed

Open access This is an open access article distributed in accordance with the Creative Commons Attribution Non Commercial (CC BY-NC 4.0) license, which permits others to distribute, remix, adapt, build upon this work non-commercially, and license their derivative works on different terms, provided the original work is properly cited, appropriate credit is given, any changes made indicated, and the use is non-commercial. See: http://creativecommons.org/licenses/by-nc/4.0/.

\section{REFERENCES}

1. Penner AM, Science S. Gender inequality in science. Science 2015;347:234-5.

2. Amering M, Schrank B, Sibitz I. The gender gap in high-impact psychiatry journals. Acad Med 2011;86:946-52.

3. Hamel MB, Ingelfinger JR, Phimister E, et al. Women in academic medicine--progress and challenges. $N$ Engl J Med 2006;355:310-2.

4. Jagsi R, Guancial EA, Worobey CC, et al. The "gender gap" in authorship of academic medical literature--a 35-year perspective. $N$ Engl J Med 2006;355:281-7.

5. Liang $\mathrm{T}$, Zhang $\mathrm{C}$, Khara RM, et al. Assessing the gap in female authorship in radiology: trends over the past two decades. $J$ Am Coll Radiol 2015;12:735-41.
6. Long MT, Leszczynski A, Thompson KD, et al. Female authorship in major academic gastroenterology journals: a look over 20 years. Gastrointest Endosc 2015;81:1440-7.

7. Mueller C, Wright R, Girod S. The publication gender gap in US academic surgery. BMC Surg 2017;17.

8. Shields L, Hall J, Mamun AA. The 'gender gap' in authorship in nursing literature. J R Soc Med 2011;104:457-64.

9. Blumenthal DM, Olenski AR, Yeh RW, et al. Sex differences in faculty RANK among academic cardiologists in the United States. Circulation 2017;135:506-17.

10. Gilboa SM, Devine OJ, Kucik JE, et al. Congenital heart defects in the United States: estimating the magnitude of the affected population in 2010. Circulation 2016;134:101-9.

11. Yedidia MJ, Bickel J. Why aren't there more women leaders in academic medicine? the views of clinical department chairs. Acad Med 2001;76:453-65.

12. Ramakrishnan A, Sambuco D, Jagsi R. Women's participation in the medical profession: insights from experiences in Japan, Scandinavia, Russia, and eastern Europe. J Womens Health 2014;23:927-34.

13. Sue DW, Capodilupo CM, Torino GC, et al. Racial microaggressions in everyday life: implications for clinical practice. Am Psychol 2007;62:271-86.

14. Basford TE, Offermann LR, Behrend TS. Do you see what I see? Perceptions of gender Microaggressions in the workplace. Psychology of Women Quarterly 2014;38:340-9.

15. Sege R, Nykiel-Bub L, Selk S. Sex differences in institutional support for junior biomedical researchers. JAMA 2015;314:1175-7.

16. Kvaerner KJ, Aasland OG, Botten GS. Female medical leadership: cross sectional study. BMJ 1999;318:91-4.

17. Pedersen LT, Bak NH, Dissing AS, et al. Gender bias in specialty preferences among Danish medical students: a cross-sectional study. Dan Med Bull 2011;58.

18. Riska E. Medical careers and feminist agendas: American, Scandinavian. and Russian women physicians: Transaction Publishers 2001

19. Gottlieb AS. Promoting academic careers of women in medicine. Maturitas 2017:96:114-5.

20. Chang S, Morahan PS, Magrane D, et al. Retaining faculty in academic medicine: the impact of career development programs for women. J Womens Health 2016;25:687-96.

21. Helitzer DL, Newbill SL, Cardinali G, et al. Narratives of participants in national career development programs for women in academic medicine: identifying the opportunities for strategic investment. $J$ Womens Health 2016;25:360-70.

22. Tsugawa $Y$, Jena AB, Figueroa JF, et al. Comparison of hospital mortality and readmission rates for Medicare patients treated by male vs female physicians. JAMA Intern Med 2017;177:206-13. 